\title{
The Crystallization and Characterization of Calcium-Magnesium- Aluminosilicate Glass-Ceramics
}

\begin{abstract}
Aliyu, Z.S.
Abstract: Calcium-magnesium-aluminosilicate (CaO.MgO. $\left.\mathrm{Al}_{3} \mathrm{O}_{3} \cdot \mathrm{SiO}_{2}\right)$ glass-ceramics was developed from the base glass system of the composition $52.00 \mathrm{wt} \% \mathrm{SiO}_{2}, 16.00 \mathrm{wt} \% \mathrm{Al}_{2} \mathrm{O}_{3}$, $12.00 \mathrm{wt}^{\%} \% \mathrm{CaO}, 8.00 \mathrm{wt} \% \mathrm{MgO}, 2.00 \mathrm{wt} \% \mathrm{~K}_{2} \mathrm{O}, 6.00 \mathrm{wt} \% \mathrm{TiO}_{2}, 0.30 \mathrm{wt} \% \mathrm{NaCl}$ and $3.70 \mathrm{wt} \%$ in this study. The study focused attention on the crystallization of $\mathrm{CaO} \cdot \mathrm{MgO} \cdot \mathrm{Al}_{3} \mathrm{O}_{3} \cdot \mathrm{SiO}_{2}$ base glass system using $363^{\circ} \mathrm{C} \& 663^{\circ} \mathrm{C}$ as nucleation and crystal growth temperatures respectively, and 1 - 4 hours as soaking time. The composition was melted at $1600^{\circ} \mathrm{C}$ for 3 hours in a muffle furnace and the molten glass was cast into rods, annealed at $600^{\circ} \mathrm{C}$ for 1 hour and finally cooled to room temperature. Due to the presence of impurities in the starting materials, the glasses produced have a brownish physical appearance. Base glasses were crystallized into glass-ceramics using double-stage heat treatment schedule, and XRD and SEM were used to characterize the produced samples. The XRD identified the crystalline phases precipitated in the residual glass matrix of the sample soaked for 4 hours as albite, quartz, wollastonite and witherite. The SEM result revealed that the microstructure of the sample is characterized by dense, circular-like and needle-like clusters alongside micro-sized voids dispersed in the residual glassy phase matrix. The density and hardness values were found to increase while weight loss decreased with increase in soaking time across the samples. The sample soaked for 4 hours has the lowest weight loss but with the highest density and hardness values making it suitable for use for abrasion due to its excellent properties.
\end{abstract}

Keywords: Crystallization, Characterization, Some Glass-ceramic Properties

\section{Introduction}

Glass-ceramics is defined as an inorganic, nonmetallic material prepared through controlled crystallization of glasses via different processing methods. The material contains at least one type of crystalline phase and a residual glassy phase [6]. Therefore, glassceramic is a solid material, partly crystalline and partly glassy, formed by controlled crystallization of glass. The properties of glassceramic material depend on the kind and percentage of crystalline phase precipitated as well as the composition of the residual glassy phase [2]. According to [13], they are produced by controlling the heat-treatment schedule from glass to achieve new material with

\footnotetext{
Aliyu, Z.S. (Department of Glass \& Silicate Technology, Ahmadu Bello University, Zaria-Nigeria)

Corresponding author: zainabsagarba@gmail.com Telephone Number: +234-817-360-3916
}

superior properties in comparison with the parent glass. The chemical composition and microstructure of the glass-ceramics determine its properties and main applications [10]. Due to the controlled crystallization process, the parent glass is transformed into a new material with improved properties. According to [7], crystallization is the process of precipitating array of crystals from less ordered glassy material. Glass as less ordered material is defined as a non-equilibrium, noncrystalline condensed state of matter that exhibits a glass transition [15]. The crystallization process of the parent glass consists of double-stage heat treatment such as nucleation and crystallization processes. During the nucleation stage, the glass is held for a while at a temperature which promotes the formation of nuclei throughout the glassy material [1]. During the crystallization stage, the temperature is increased to allow nuclei to 
grow. Therefore, crystallization of a glassy material is accomplished by subjecting suitable glass to a carefully regulated heat treatment schedule, which results in nuclei formation and subsequent crystal growth within the glass [5].

To enhance both nucleation rate and crystal growth rate, nucleating agents are often incorporated to the glass melt. There are wider varieties of nucleating agents for different glass-ceramic systems, with the most common being metallic oxides such as $\mathrm{TiO}_{2}, \mathrm{ZrO}_{2}$, $\mathrm{Cr}_{2} \mathrm{O}_{3}$ and $\mathrm{P}_{2} \mathrm{O}_{5}$ among others to enhance the precipitation of crystalline phases in $\mathrm{CaO} \cdot \mathrm{MgO} \cdot \mathrm{Al}_{2} \mathrm{O}_{3} \cdot \mathrm{SiO}_{2}$ (CMAS) and other glass-ceramic materials [3]. Basically, glassceramics are superior to their corresponding parent glasses as a result of excellent properties like mechanical, chemical, thermal and biological properties and this allows the formation of reproducible fine-grained and uniform microstructure without micro crack or other porosity [5]. It is possible to design their microstructure for a given application because their properties can be tailored by changes in composition and heat treatment [3]. A glassceramic is usually not fully crystalline with the microstructure being $50-95 \%$ crystalline and the remainder being residual glassy [2]. When a primary glass undergoes heat treatment, one or more crystalline phases may form, and both the compositions of the crystalline phases and residual glass are different from the parent glass.

In order to develop a glass-ceramics with desirable properties, it is important to control the crystallization process so that even distribution of crystals can be formed [9]. In glass-ceramic materials, selecting optimum composition and controlled heat treatment schedule allows the precipitation of a wide range of microstructures, and consequently, various specific properties are achieved and this further allowed these materials to be used in diverse technological applications. Glass- ceramic materials have a wide variety of base glass systems which can be prepared from a broad spectrum of chemical compositions focusing majorly on the final area of application. According to [11], the most widely studied base glass systems include; $\mathrm{MgO} \cdot \mathrm{Al}_{2} \mathrm{O}_{3} \cdot \mathrm{SiO}_{2}$ (MAS), $\mathrm{CaO} \cdot \mathrm{Al}_{2} \mathrm{O}_{3} \cdot \mathrm{SiO}_{2}$ (CAS), $\mathrm{Li}_{2} \mathrm{O} \cdot \mathrm{Al}_{2} \mathrm{O}_{3} \cdot \mathrm{SiO}_{2}$ (LAS) and $\mathrm{CaO} \cdot \mathrm{MgO} \cdot \mathrm{Al}_{2} \mathrm{O}_{3} \cdot \mathrm{SiO}_{2}$ (CMAS) among others. [4], reported that the composition of a parent glass is different from the precipitated crystalline phases as residual glassy phase changes its composition and density as a function of the crystallization process. Similarly, chemical durability directly affects strength and hardness of glass-ceramic sample which significantly influences abrasion [12].

The aim of this work is to study the crystallization and microstructure of calciummagnesium-aluminosilicate

(CaO.MgO. $\mathrm{Al}_{2} \mathrm{O}_{3} \cdot \mathrm{SiO}_{2}$ ) primary glass system in relation to the effect of the nucleating agent on composition as well as some properties for the beneficial application.

\section{Experimental Procedure}

\section{A Glass preparation and production}

The batch composition of the studied glass is as follows; $52.00 \mathrm{wt} \% \mathrm{SiO}_{2}, 16.00 \mathrm{wt} \% \mathrm{Al}_{2} \mathrm{O}_{3}$, $12.00 \mathrm{wt} \% \quad \mathrm{CaO}, \quad 8.00 \mathrm{wt}^{\%} \% \quad \mathrm{MgO}, \quad 2.00 \mathrm{wt} \%$ $\mathrm{K}_{2} \mathrm{O}, \quad 6.00 \mathrm{wt} \% \quad \mathrm{TiO}_{2}, \quad 0.30 \mathrm{wt} \% \quad \mathrm{NaCl}$ and $3.70 \mathrm{wt} \%$ trace. The batch composition was thoroughly mixed and poured into a crucible which was transferred into an electrically heated furnace. The batch was melted at $1600^{\circ} \mathrm{C}$ for 3 hours with an interval of 30 minutes swirling to ensure complete homogenization of the melt. Thereafter, the melt was cast into rods using a mould and the rods were quickly transferred to a muffle furnace preheated at $600^{\circ} \mathrm{C}$ for annealing to reduce the residual stresses. The rods were gradually cooled to room temperature and 
physical appearance of the samples was observed.

\section{B Heat Treatment Regime}

The glass-ceramic samples were obtained by controlled nucleation and crystallization processes via double stage heat-treatment regimes. The glasses were crystallized at $363^{\circ} \mathrm{C}$ and $663^{\circ} \mathrm{C}$ as nucleation and crystal growth temperatures respectively. The samples were soaked for ranges of 1-4 hours duration. After the heat treatment, the muffle furnace was switched off and the samples were allowed to cool gradually to room temperature.

\section{X-ray Diffraction (XRD)}

The presence of the crystalline phase in a sample heat-treated for 4 hours duration were identified using Philips/ PANanalytical X'pert Pro MPD Powder Diffractometer with an X'celerator detector, and $\mathrm{Fe}$ filtered $\mathrm{Cu} \mathrm{K} \alpha$ radiation in the 2 range from $5^{\circ}$ to $100^{\circ}$ operating at $40 \mathrm{kV}$ and $35 \mathrm{~mA}$.

The precipitated crystalline phases were detected using X' pert high score software.

\section{Scanning Electron Microscope (SEM)}

The morphological characteristics of the crystallized sample heat-treated for 4 hours duration were carried out using a scanning electron microscope (SEM) JEOL Model JSM7500F. Scanning electron microscopy (SEM) characterization was carried out using freshly fractured surface crystalline sample etched through immersion in a $1 \mathrm{M} \mathrm{HF}$ aqueous solution for 30 minutes. Thereafter, the sample was thoroughly washed with distilled water and oven-dried at $110^{\circ} \mathrm{C}$ for 2 hours.

\section{E Physico-Mechanical and Chemical Characterization}

\section{i. Density measurement}

Density measurement of four samples heattreated for 1-4 hours' time were carried out using the Standard Archimedes Principle. The weights of the four samples heat-treated for 4 hours duration in the air and in distilled water were measured using an electrical digital weighing balance. Their respective densities were calculated using the expression as follows:

$$
\text { Density }=\frac{D}{w-s} \mathrm{~g} / \mathrm{cm}^{3}
$$

where, $\mathrm{D}$ is the weight of sample in the air (g), $\mathrm{W}$ is the weight of sample soaked in distilled water (g) and $\mathrm{S}$ is the weight of sample suspended in distilled water $(\mathrm{g})$.

\section{ii. Hardness measurement}

Measurement of four samples heat-treated for 1 to 4 hours was carried out using Micro Vickers Hardness Tester Model MV1- PC. 0.3 Kgf load was applied to each sample and the indenter was square based diamond pyramid.

\section{iii. Chemical Durability Test}

Four samples heat-treated for 1-4 hours were oven dried at $110^{\circ} \mathrm{C}$ for 4 hours duration and then weighed to the nearest $0.1 \mathrm{mg}$ as (Wa). Each sample was individually immersed in 50 $\mathrm{ml}$ glass bottle containing $1 \mathrm{M} \mathrm{HCl}$. The bottle was closed with its cap and then placed in the oven at $90^{\circ} \mathrm{C}$ for 10 hours. Thereafter, each sample was thoroughly washed and then oven dried at $110^{\circ} \mathrm{C}$ for 1 hour to achieve a constant weight. Thereafter, each of the samples were reweighed to obtain the mass after immersion as (Wb), then, total weight loss per cent of each sample was calculated and chemical durability was expressed as weight loss per cent. 


\section{Results and Discussion}

Each rod of glass sample yielded a brownish colouration. The undesirable colour might be due to an $\mathrm{Fe}^{3+}$ charge transfer formed by trace impurities of iron oxide present in the starting materials [8]. The nucleation and crystallization processes were completed via double stage heat-treatment schedules. Figure 1 shows Xray diffraction pattern of the sample subjected to heat treatment for 4 hours duration. The crystalline phases precipitated in the sample are quartz $\left(\mathrm{SiO}_{2}\right)$, albite $\left(\mathrm{Na}_{2} \mathrm{O} \cdot \mathrm{Al}_{2} \mathrm{O}_{3} \cdot 3 \mathrm{SiO}_{2}\right)$, wollastonite $\left(\mathrm{CaO} \cdot \mathrm{SiO}_{2}\right)$ and witherite $\left(\mathrm{BaCO}_{3}\right)$. This is in agreement with [1] and [11] who stated that glass-ceramic material must contain at least one or more crystalline phases dispersed in the residual glassy phase.

The SEM image in Plate 1 is the microstructure of sample heat-treated for 4 hours duration. The microstructure is characterized by circular-like and flake-like crystals alongside voids all dispersed in matrix of the residual glassy phase.

Figure 2 shows the density values of the samples that were soaked for 1 to 4 hours. The density values were increasing gradually as heat treatment times were increasing progressively from 1 to 4 hours. The slight increase in density was due to precipitation of large volume of crystalline phases dispersed in the glassy phase. According to [14] and [3], the density of glass-ceramic material is always larger than the density of its corresponding parent glass. In a similar way, density variation revealed the degree of crystallization processes when the difference between the densities of glass-ceramic and the corresponding parent glass is significantly great.

Figure 3 depicts the hardness results of samples heat-treated for 1 to 4 hours duration. The results revealed that there was

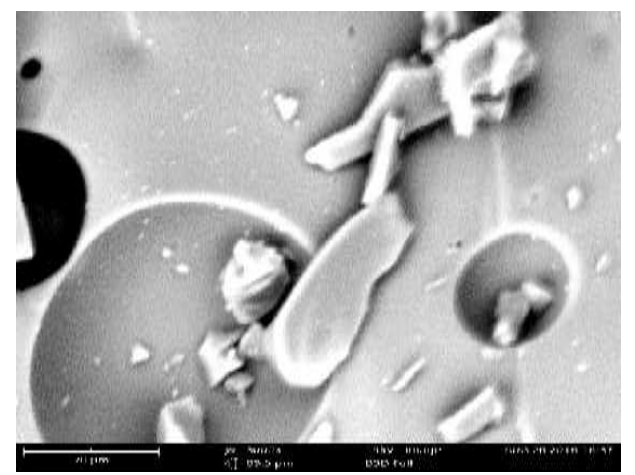

Plate 1: SEM micrograph of glass-ceramic sample soaked for 4 hours duration.

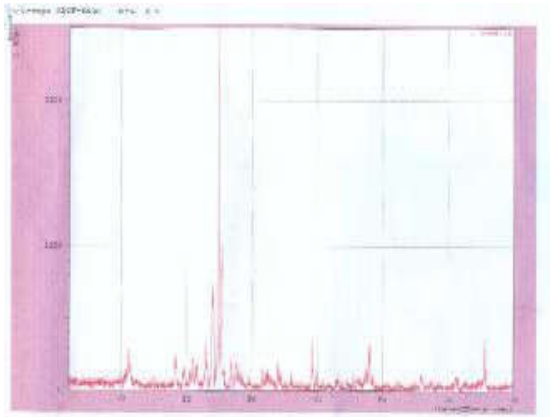

Figure I: XRD patterns of glass-ceramic sample Heat treated for 4 hours

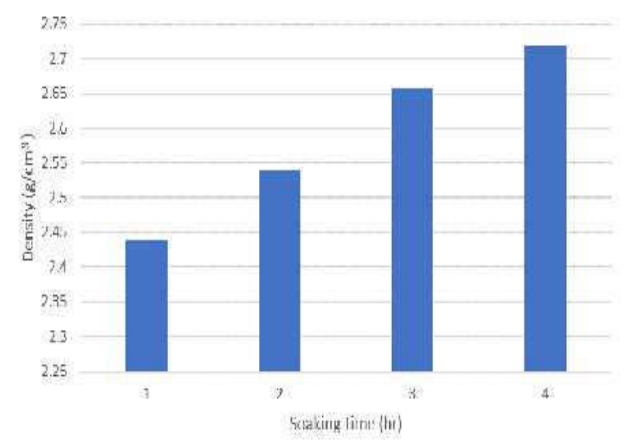

Figure 2: Variation of density and soaking time in the heat treatment furnace from 1 to 4 hours duration

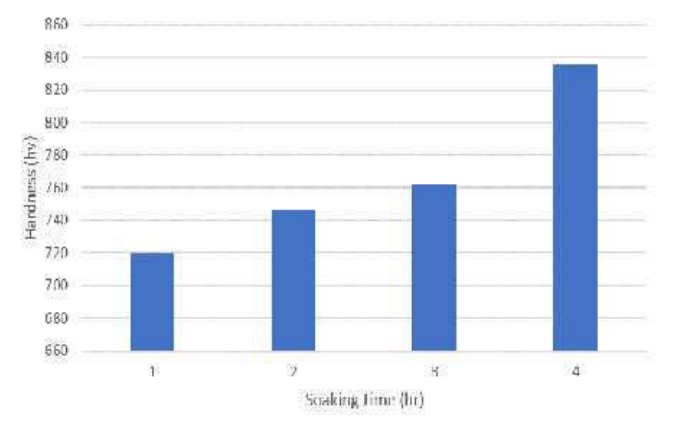

Figure 3: Variation of hardness and soaking time in the heat treatment furnace from 1 to 4 hours duration. 
a gradual increase of hardness as heat treatment time increases from 1 to 4 hours. This result is in harmony with [2], who stated that hardness changes with precipitation of large volume of crystalline phases and prolong soaking time. In addition, the increase in hardness might result from viscous flow formation induced by prolonging soaking time.

Figure 4 portrays the weight loss results of samples soaked for 1-4 hours duration. A progressive decrease in weight loss was noticeable as soaking time (1-4 hours) was increasing across samples that were immersed in $1 \mathrm{M} \mathrm{HCl}$ aqueous solution at $90^{\circ} \mathrm{C}$ for 10 hours.

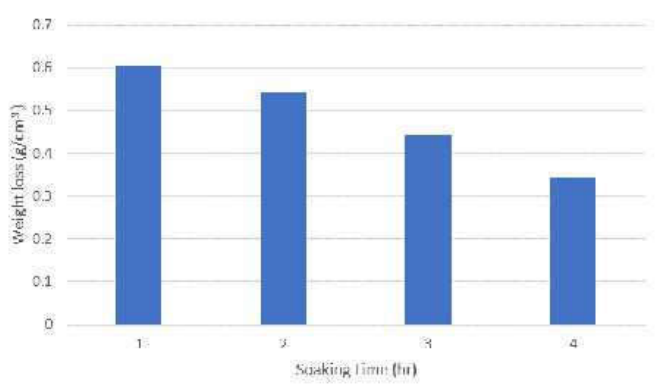

Figure 4: Weight loss values of samples that were soaked for 1-4 hours duration in $1 \mathrm{M} \mathrm{HCl}$

This is in agreement with [1, 11], who reported that decrease in weight loss would be noticeable when glass-ceramic material is heat-treated for a considerable period, as prolong soaking allows the precipitation of large volume of crystalline phases dispersed in the residual glassy phase, and this hinders weight loss. Therefore, the reduction of weight loss observed in the sample heattreated for 4 hours duration was due to precipitation of crystalline phases dispersed in the matrix of a residual glassy phase.

\section{Conclusion}

The characterization and some properties of calcium-magnesium-aluminosilicate $\quad(\mathrm{CaO}$. $\mathrm{MgO} \cdot \mathrm{Al}_{2} \mathrm{O}_{3} \cdot \mathrm{SiO}_{2}$ ) glass-ceramic were studied and the conclusion has been drawn as follows:

1. The physical appearance of calciummagnesium-aluminosilicate $\quad(\mathrm{CaO}$. $\left.\mathrm{MgO} \cdot \mathrm{Al}_{2} \mathrm{O}_{3} \cdot \mathrm{SiO}_{2}\right)$ primary glass system was brownish due the presence of iron oxide impurities in the starting materials.

2. The crystalline phases dispersed in the residual glassy phase as identified by XRD were quartz, albite, wollastonite and witherite.

3. The microstructural configuration of the sample heat-treated for a duration of 4 hours as detected by SEM is characterized by circular-like and flakelike crystals randomly distributed alongside fewer micro-sized voids dispersed in the residual glassy phase.

4. The sample that was soaked for 4 hours duration has the highest density and hardness values as well as the lowest weight loss value and this might result from the presence of a considerable volume of crystalline phases embedded in the residual glassy phase. Therefore, the sample can be applied for abrasion resistance usage.

\section{References}

[1.] Aliyu, Z.S. "Effect of Titania Addition on the Microstructure and Crystallization Behaviour of Glass-ceramics Prepared from Local Raw 013 Materials", Science World Journal, vol.15, no. 1, 2020, pp. 7-10.

[2.] Aliyu, Z.S. "Effect of Titania Addition on the Crystallization Characteristics of Glass - ceramics Materials", Science World Journal, vol.14, no. 3, 2019, pp. 61-64.

[3.] Aliyu, Z.S. "Effect of Nucleating Agent and Heat Treatment Time on the Crystallization Characteristics of $\mathrm{CaO}-\mathrm{MgO}-$ $\mathrm{Al}_{2} \mathrm{O} 3-\mathrm{SiO} 2 \mathrm{Base}$ Glass System", Proceedings of the National Conference on the Role of Engineering 
in the Diversification of Nigerian Economy. National Engineering Conference. Ahmadu Bello

University, Zaria, November $14^{\text {th }}-17^{\text {th }}$ November, 2018, pp. 661-664.

[4.] Alexander, K. and Mario, P. "Evaluation of the Degree of Crystallization in Glass- ceramics by Density Measurements", Journal of the European Ceramic Society, vol. 19, 1999, pp. 649-654.

[5.] Debasis, P.M. and Sudip, K.D. "Influence of $\mathrm{TiO} 2$ Content on the Crystallization and Microstructure of Machinable Glass-ceramics", Journal of Asian Ceramic Societies, vol. 4, no. 1, 2016, pp. 55-60.

[6.] Deubener, J., Allix, M., Davis, M.J., Duran, A., Hoche, T., Honma, T., Komatsu, T., Kruger, S., Mitra, I., Muller, R., Nakane, S., Pascual, M.J., Schmelzer, J.W.P., Zanotto, E.D. and Zhou, S. "Updated Definition of Glass-ceramics", Journal of Non-Crystalline Solids, ${ }^{015}$ vol.501, 2018, pp. 3-10.

[7.] El-Meliegy, E. and Richard V. "Glasses and Glass-ceramics for Medical Applications", Springer, New York. N.Y. USA. 2012, pp. 111.

[8.] Erinco, K., Christain, P., Michael, K., Yongfeng, H., Thomas, H. and Christain, R. "The Effect of $\mathrm{TiO}_{2}$ on Nucleation and Crystallization of a Li2O-Al2O3-SiO2 Glass Investigated by XANES and STEM", Journal of Scientific Reports, 2018, 8:2929/ DOI: 10.1038/s41598-018-21227-x

[9.] Holand, W. and Beall, G. "GlassCeramics Technology", The American Ceramic Society Publishers, Westerville. 2002.

[10.] Holand, W., Rheinberger, V. and Schweiger, M. "Control of Nucleation in Glass- Ceramics", The Royal Society Publishers, vol.361, 2016, pp. 575-589.

[11.] Junfeng, K., Zhiyan, C., Xigang, Z. and Sha, Z. "Effect of Replacement of $\mathrm{Na}_{2} \mathrm{O}$ by $\mathrm{Fe}_{2} \mathrm{O}_{3}$ on the Crystallization Behaviour and Acid Resistance of Magnesium-AluminoSilicate Glass-ceramic", Journal of NonCrystalline Solids", DOI:10.1016/j.jnoncrysol.2018.09.013.
[12.] Khalissa, A., Aitana, T., Abdellah, C., Fausto, R. and Juan, R. "Kinetic Study on the Effect of Adding P2O5 to the LMAS Glassceramics", Boletin De La Sociedad Espanola De Ceramica Y Vidrio, vol. 185, 2020, pp. 1-12.

[13.] Naruporn, M., Pornchanok, L. and Witoon, T. "Characterization and Properties of Lithium Disilicate Glass-ceramics in the $\mathrm{SiO}_{2}-\mathrm{Li} 2 \mathrm{O}-\mathrm{K}_{2} \mathrm{O}-\mathrm{Al}_{2} \mathrm{O} 3$ Base Glass System for Dental Application", Advance in Materials Science and Engineering, 2013, pp. 1-11.

[14.] Salman, S.M., Salama, S.N. and AboMosallam, H.A. "Crystallization Characteristics and Physico-Chemical Properties of Glassceramics Based on Li2O-ZnO-SiO2 System", Ceramica Y Vidrio, vol.56, 2017, pp. 205-214.

[15.] Strnad, Z. “ Glass-ceramics Materials in Glass Science and Technology", Elsevier, Amsterdam, the Netherlands.

[16.] Edgar, D.Z. and John, C.M. "The Glassy State of Matter: Its definition and Ultimate Fate", Journal of Non-Crystalline Solids, vol. 471, 2017, pp. 490-495 